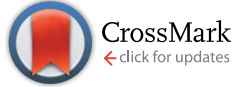

Cite this: RSC Adv., 2017, 7, 8402
Received 24th October 2016 Accepted 9th January 2017

DOI: 10.1039/c6ra25741k

www.rsc.org/advances

\section{Optical properties and fluorescence quenching of carbazole containing ( $D-\pi-A$ ) push-pull chromophores by silver nanoparticles: a detailed insight via an experimental and theoretical approach}

\begin{abstract}
Abdullah M. Asiri, ${ }^{\text {ab }}$ Osman I. Osman, ${ }^{a}$ Saad H. Al-Thaqafy ${ }^{a}$ and Salman A. Khan ${ }^{\star a}$
(4Z)-4-[(9-Ethyl-9H-carbazol-3-yl)methylidene]-2-phenyl-1,3-oxazol-5(4H)-one (ECPO) was prepared by the one-pot multi-component reaction of 9-ethyl-9H-carbazole-3-carbaldehyde, hippuric acid, anhydrous sodium acetate and acetic anhydride under microwave irradiation. The structure of ECPO was confirmed by elemental analysis and spectral studies $\left({ }^{1} \mathrm{H}\right.$ and $\left.{ }^{13} \mathrm{C} N M R, F T-I R\right)$ and theoretically by Density Functional Theory (DFT). The experimental and simulated electronic absorption and fluorescence spectra of ECPO have been studied in solvents of different polarities. They are in good agreement with each other. The data were used to study solvatochromic properties such as excitation coefficient, Stokes shift, oscillator strength, transition dipole moment, and fluorescence quantum yield. The wavelength maxima showed red shifts with increasing solvent polarity from $n$-hexane to DMSO. ECPO undergoes solubilization in different micelles and may be used as a probe for determining the critical micelle concentration (CMC) of CTAB and SDS. The interaction of colloidal silver nanoparticles (AgNPs) with ECPO dye was studied in ethanol and ethylene glycol using steady state fluorescence quenching measurements. The Stern-Volmer quenching rate constant $\left(K_{\text {sv }}\right)$ was calculated to be $5.28 \times$ $10^{7} \mathrm{M}^{-1}$ and $3.48 \times 10^{7} \mathrm{M}^{-1}$ in ethanol and ethylene glycol, respectively. ECPO's highly promising NLO character was complemented by NBO investigation.
\end{abstract}

\section{Introduction}

Physicochemical, photophysical and optical properties are the most fundamental properties of organic fluorochromic materials. Various physicochemical parameters such as excitation coefficient, Stokes shift, oscillator strength, transition dipole moment, and fluorescence quantum yield of molecules are used to determine the physical behavior of the organic chromophores. ${ }^{\mathbf{1} 2}$ Organic compounds containing long $\pi$-bond conjugated systems are known as chromophores, with these $\pi$ conjugated moieties being responsible for their colours. ${ }^{3}$ Donor-acceptor $(\mathrm{D}-\pi-\mathrm{A})$ groups containing chromophores are responsible for the fluorescence emission due to intramolecular charge transfer from the donor group to the acceptor group through $\pi$-bond conjugation. ${ }^{4} \mathrm{D}-\pi$-A containing chromophoric materials have received extensive consideration due to their prospective applications in organic light-emitting diodes, ${ }^{\mathbf{5}}$ chemosensors for the detection of various metal ions, ${ }^{6}$ organic

${ }^{a}$ Department of Chemistry, Faculty of Science, King Abdulaziz University, P. O. Box 80203, Jeddah 21589, Saudi Arabia. E-mail: sahmad_phd@yahoo.co.in

${ }^{b}$ Center of Excellence for Advanced Materials Research (CEAMR), King Abdulaziz University, P. O. Box 80203, Jeddah 21589, Saudi Arabia fluorescent chemosensors, ${ }^{7}$ dye-sensitized solar cells, photoconductors, switching devices, nonlinear optics, organic fieldeffect transistors and solid-state dye lasers. ${ }^{8}$ However, in most cases, chromophoric florescence materials become weakly emissive with no fluorescence in the aggregate or solid state. ${ }^{9}$ This kind of cause is known as the tarnished aggregationcaused quenching (ACQ) effect due to strong pep stacking interactions, which restrict the scope of the application fields. ${ }^{10}$ Nitrogen and oxygen containing heterocyclic compounds such as isoxazole ${ }^{11}$ and oxazole ${ }^{12}$ have received a great deal of attention in the literature because of their role as pharmacophores of notable historical importance. ${ }^{13}$ Among these heterocyclic systems, the azlactones, which are donor-acceptor chromophore derivatives, have their heteroaromatic and biological fundamental properties such as antiviral, ${ }^{\mathbf{1 4}}$ antimicrobial, ${ }^{15}$ anticonvulsant, ${ }^{\mathbf{1 6}}$ anti-HIV,${ }^{\mathbf{1 7}}$ antifungal and anti-mycobacterial activities $^{\mathbf{1 8}}$ been carefully studied. On the other hand, azlactone chromophores are used as photo-luminescent materials. ${ }^{19}$ Our current interest is to develop synthetic strategies for obtaining functionalized and interesting molecules with important properties such as donor-acceptor containing azlactones. ${ }^{20}$ These kinds of compounds have been attractive for physicochemical applications since they exhibit high 
fluorescence in both solution and solid states when exposed to yellow light, which makes them appropriate for designing electroluminescent materials. ${ }^{21-23}$ In our search for new donoracceptor chromophores, we report here a one-pot synthesis of (4Z)-4-[(9-ethyl-9H-carbazol-3-yl)methylidene]-2-phenyl-1,3-oxazol-5(4H)-one (ECPO) by multi-component reaction of hippuric acid, 9-ethyl-9H-carbazole-3-carbaldehyde, anhydrous sodium acetate and acetic anhydride under microwave irradiation and its physicochemical, DFT and fluorescence quenching by silver nanoparticle were studied.

\section{Experimental}

\section{Chemicals and reagents}

The 9-ethyl-9H-carbazole-3-carbaldehyde, anhydrous sodium acetate, acetic anhydride and hippuric acid were purchased from Acros Organic. Other reagents and solvents (A.R.) were obtained commercially and used without further purification, except dimethylformamide (DMF), ethanol and methanol.

\section{Apparatus}

The reaction was carried out in a commercially available Samsung microwave oven at 210 watts, i.e. $30 \%$ microwave power. The melting points were recorded on a Thomas Hoover capillary melting apparatus without correction. ${ }^{1} \mathrm{H}-\mathrm{NMR}$ and ${ }^{13} \mathrm{C}-\mathrm{NMR}$ experiments were performed at room temperature in $\mathrm{CDCl}_{3}$ on a Brucker DPX $600 \mathrm{MHz}$ spectrometer using tetramethyl silane (TMS) as an internal standard. FT-IR spectra were recorded on a Nicolet Magna 520 FT-IR spectrometer. UV-Vis electronic absorption spectra were acquired on a Shimadzu UV-1650 PC spectrophotometer. Absorption spectra were collected using a $1 \mathrm{~cm}$ quartz cell. Steady state fluorescence spectra were measured using Shimadzu RF 5301 PC spectrofluorophotometer using a rectangular quartz cell. Emission spectra were monitored at right angle. All fluorescence spectra were blank subtracted before proceeding in data analysis.

\section{Synthesis of (4Z)-4-[(9-ethyl-9H-carbazol-3-yl)methylidene]-2- phenyl-1,3-oxazol-5(4H)-one (ECPO)}

(4Z)-4-[(9-Ethyl-9H-carbazol-3-yl)methylidene]-2-phenyl-1,3-oxazol$5(4 H)$-one (ECPO) was prepared by mixing equimolar quantities of hippuric acid, 9-ethyl-9H-carbazole-3-carbaldehyde and anhydrous sodium acetate were dissolved in acetic anhydride $(3 \mathrm{ml})$ and silica gel $(2 \mathrm{~g})$ was add as solid support, the reaction mixture was heated inside a microwave oven for $5 \mathrm{~min}$ at $210 \mathrm{~W}$, i.e. $30 \%$ microwave power. When the reaction was complete, the reaction mixture was cooled and the product was extracted with dichloromethanein. Removal of the solvent under reduced pressure. Then recrystallized from distilled ethanol and chloroform. Yellow solid: $\mathrm{mp} 210^{\circ} \mathrm{C}$; anal. calc. for $\mathrm{C}_{24} \mathrm{H}_{18} \mathrm{~N}_{2} \mathrm{O}_{2}$ : C, 78.67, H, 4.95; N, 7.65; found: C, 78.63, H, 4.93, N, 7.62; ${ }^{1} \mathrm{H}$ NMR $\left(600 \mathrm{MHz} \mathrm{CDCl}_{3}\right)$ $(\delta / \mathrm{ppm}): 8.94(\mathrm{~s}, 1 \mathrm{H}), 8.42-7.29(\mathrm{~m}, 12 \mathrm{H}, \mathrm{CH}$ aromatic), 4.424.36 (q, $\left.\mathrm{CH}_{2}-\mathrm{CH}_{3}\right), 1.49-1.45\left(\mathrm{t}, \mathrm{CH}_{2}-\mathrm{CH}_{3}\right) ;{ }^{13} \mathrm{C} \mathrm{NMR}\left(\mathrm{CDCl}_{3}\right) \delta$ : $168.31(\mathrm{C}=\mathrm{O}), 161.94(\mathrm{C}=\mathrm{N}), 141.78,140.58,133.93,132.80$, 130.75, 130.32, 128.09, 126.54, 126.12, 126.06, 124.91, 123.70, 123.13, 120.86, 120.12 (Ar-C), 109.08, 109.02, 37.93, 13.19; IR (KBr) $\nu_{\max } / \mathrm{cm}^{-1}: 2954(\mathrm{C}-\mathrm{H}), 1658(\mathrm{C}=\mathrm{O}), 1584(\mathrm{C}=\mathrm{C}), 1544$ $(\mathrm{C}=\mathrm{N}), 1253(\mathrm{C}-\mathrm{O})$.

\section{Results and discussion}

\section{Chemistry of ECPO}

(4Z)-4-[(9-Ethyl-9H-carbazol-3-yl)methylidene]-2-phenyl-1,3-oxazol$5(4 H)$-one (ECPO) was synthesized by an equimolar quantities of multicomponent reaction of hippuric acid, 9-ethyl-9H-carbazole3-carbaldehyde and anhydrous sodium acetate were dissolved in acetic anhydride Scheme $1 .^{24}$ The purified dye was characterized by the FT-IR, ${ }^{1} \mathrm{H}-\mathrm{NMR},{ }^{13} \mathrm{C}-\mathrm{NMR}$ and elemental analysis. FT-IR spectrum characteristic band at $1680 \mathrm{~cm}^{-1}$ for the aldehyde $\nu(\mathrm{C}=\mathrm{O})$ stretch is shifted to a lower frequency of $1658 \mathrm{~cm}^{-1}$ in ECPO. This is due to the utilization of $\mathrm{C}=\mathrm{O}$ in the formation of oxazol-5 $(4 \mathrm{H})$ one. The IR spectrum of ECPO shows a characteristic band at 1544 $\mathrm{cm}^{-1}$ due to presence $\mathrm{C}=\mathrm{N}$ group. It also shows a sharp peak at $1253 \mathrm{~cm}^{-1}$ due to the presence of $\mathrm{C}-\mathrm{O}$ stretch as a confirmation for the formation of oxazole ring. The ${ }^{1} \mathrm{H}-\mathrm{NMR}$ spectra of ECPO measured at room temperature shows one singlet at $\delta 8.94$ for the $\mathrm{CH}=\mathrm{C}$. The appearance of multiplets at $\delta 8.42-7.29$ is due to aromatic protons, one quartet and one triplet at $\delta 4.42-4.36$ and $\delta 1.49-1.45$, respectively, for the ethyl group in the ECPO. Moreover, ${ }^{13} \mathrm{C}-\mathrm{NMR}$ spectrum of ECPO was recorded in $\mathrm{CDCl}_{3}$ and spectral signals are in good agreement with the probable structure. The ${ }^{13} \mathrm{C}$ NMR carbonyl carbon of ECPO usually appeared at $\delta 168.31$. The ${ }^{13} \mathrm{C}$-NMR spectra also showed signals in the range of $\delta 130.75-$ $120.12 \mathrm{ppm}$, due to the aryl carbon atoms. The details of ${ }^{13} \mathrm{C}-\mathrm{NMR}$ spectra of all compounds are given in the Experimental section.

\section{Spectral behavior of ECPO in different media}

The absorption and fluorescence spectra of the (4Z)-4-[(9-ethyl-9Hcarbazol-3-yl)methylidene]-2-phenyl-1,3-oxazol-5(4H)-one (ECPO) dye $\left(1 \times 10^{-5} \mathrm{M}\right)$ were obtained at room temperature $\left(22^{\circ} \mathrm{C}\right)$ in various organic solvents with different polarity, such as ethanol, methanol, dimethylsulfoxide, dimethylformamide, chloroform, dichloromethane, carbon tetrachloride, acetonitrile, dioxan,

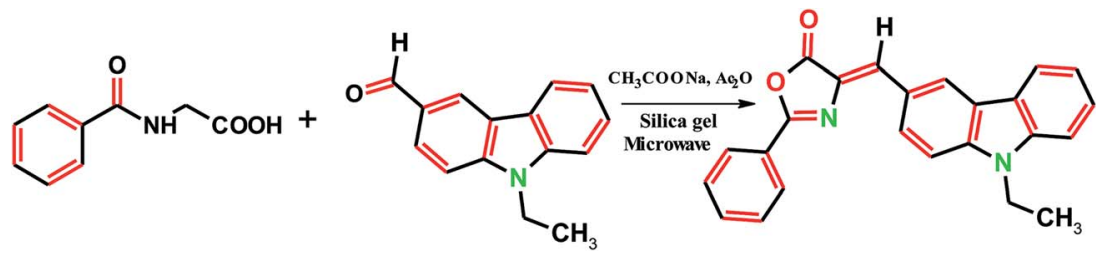

Scheme 1 Schematic diagram of ECPO. 
tetrahydrofuran. These spectra are shown in Fig. 1 and 2 and the corresponding spectral data are summarized in Table 1.

As Fig. 1 shows, in all solvent tested, the main absorption band of ECPO, is located in the spectral range 431-447 nm. It is largely red-shifted with increasing solvent polarity ( $c a .16 \mathrm{~nm}$ on going from $n$-hexane to DMSO). These features indicate a strongly allowed $\pi-\pi^{*}$ transition with charge transfer characters. ${ }^{25}$ The charge transfer occurs from the ethyl carbazole to the keto group, which is restricted due to the hydrogen bonding interaction between solvent molecules and the electron lone pair on the donor group (ethyl carbazole).

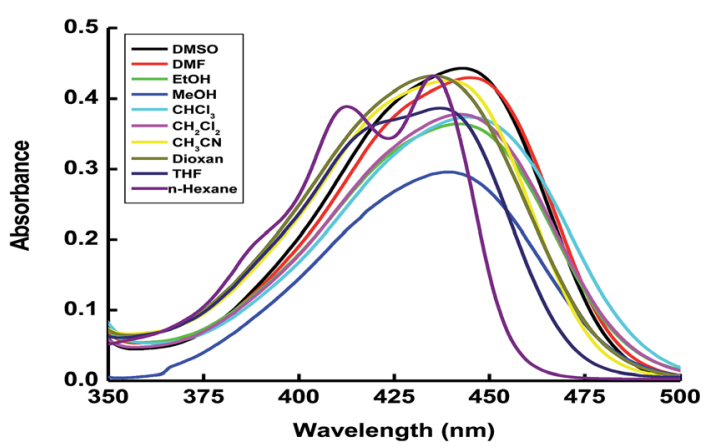

Fig. 1 Absorbance spectra of $1 \times 10^{-5} \mathrm{~mol} \mathrm{dm}^{-3}$ of the ECPO dye in different solvents.

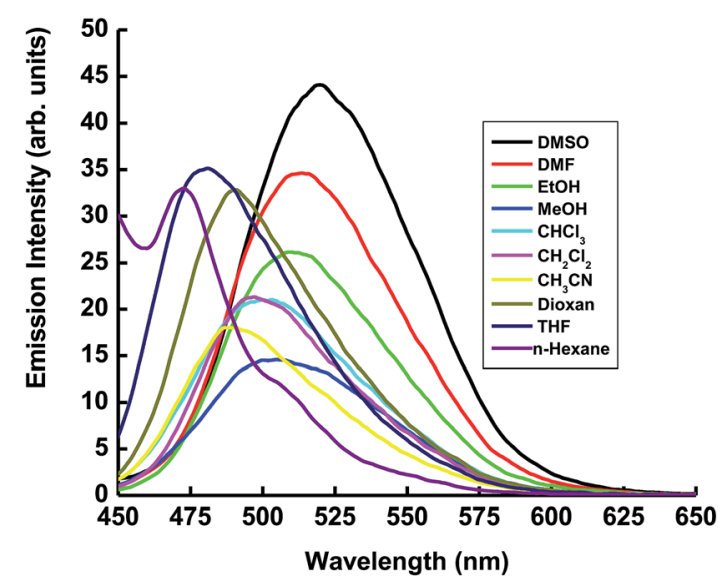

Fig. 2 Emission spectra of $1 \times 10^{-5} \mathrm{~mol} \mathrm{dm}^{-3}$ of the ECPO dye in different solvents.
The fluorescence spectrum suffers a strongly bathochromic shift as the solvent polarity increased (see Fig. 2). This red shift (ca. $48 \mathrm{~nm}$ ) in the emission maximum from $472 \mathrm{~nm}$ in $n$-hexane to $520 \mathrm{~nm}$ in DMSO observably indicates that intensively photoinduced intramolecular charge transfer takes place within the molecule in the singletexcited state. ${ }^{26}$

The energy of absorption $\left(E_{\mathrm{a}}\right)$ and emission $\left(E_{\mathrm{f}}\right)$ spectra of ECPO in different solvents are correlated with the empirical Dimroth polarity parameter $E_{\mathrm{T}}(30)$ of the solvent (Fig. 3). ${ }^{27} \mathrm{~A}$ linear correlation between the energy of absorption and emission versus polarity of solvents was obtained (eqn (1) and (2)), implying potential application of these parameters to probe the microenvironment of ECPO.

$$
\begin{aligned}
& E_{\mathrm{a}}=77.19-0.015 \times E_{\mathrm{T}}(30) \\
& E_{\mathrm{f}}=70.97-0.121 \times E_{\mathrm{T}}(30)
\end{aligned}
$$

Analysis of solvatochromic behavior allows estimating the difference in the dipole moment between the excited and ground states $\left(\Delta \mu_{\mathrm{e}}-\Delta \mu_{\mathrm{g}}\right)$. This was achieved by applying the simplified Lippert-Mataga eqn (3) and (4). ${ }^{26}$

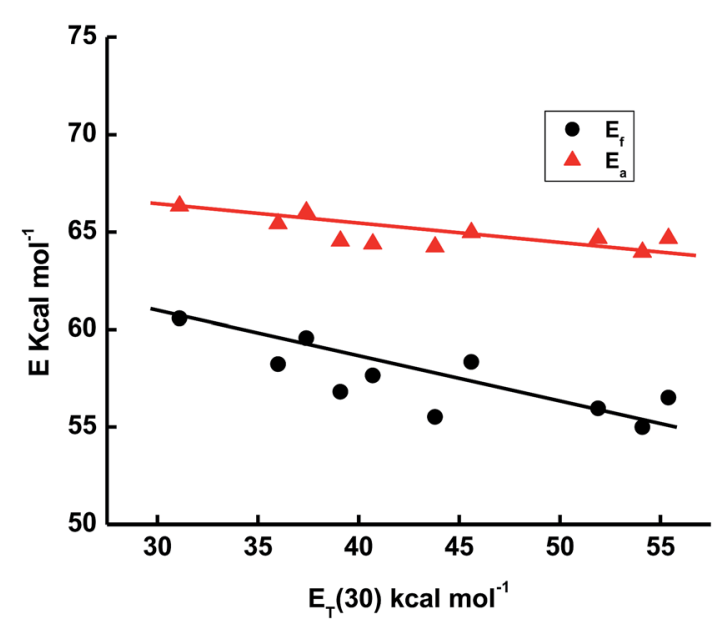

Fig. 3 Plot of energy of absorption $\left(E_{\mathrm{a}}\right)$ and emission $\left(E_{\mathrm{f}}\right)$ versus $E_{\mathrm{T}}(30)$ for the elected solvents.

\begin{tabular}{|c|c|c|c|c|c|c|c|c|c|c|}
\hline Solvent & $\Delta f$ & $E_{\mathrm{T}}^{\mathrm{N}}$ & $E_{\mathrm{T}}(30) / \mathrm{kcal} \mathrm{mol}^{-1}$ & $\lambda_{\mathrm{ab}} / \mathrm{nm}$ & $\lambda_{\mathrm{em}} / \mathrm{nm}$ & $\varepsilon \mathrm{M}^{-1} \mathrm{~cm}^{-1}$ & $f$ & $\mu_{12}$ debye & $\Delta \bar{\nu} / \mathrm{cm}^{-1}$ & $\phi_{\mathrm{f}}$ \\
\hline DMSO & 0.266 & 0.441 & 54.1 & 447 & 520 & 44700 & 0.56 & 7.20 & 3141 & 0.19 \\
\hline DMF & 0.263 & 0.404 & 43.8 & 445 & 515 & 42900 & 0.52 & 7.20 & 3054 & 0.15 \\
\hline $\mathrm{MeOH}$ & 0.299 & 0.762 & 55.4 & 442 & 506 & 29500 & 0.33 & 5.55 & 2862 & 0.09 \\
\hline $\mathrm{CHCl}_{3}$ & 0.217 & 0.259 & 39.1 & 443 & 503 & 37300 & 0.40 & 6.12 & 2693 & 0.10 \\
\hline $\mathrm{CH}_{2} \mathrm{Cl}_{2}$ & 0.255 & - & 40.7 & 444 & 496 & 37830 & 0.35 & 5.72 & 2361 & 0.11 \\
\hline THF & 0.148 & 0.210 & 37.4 & 433 & 480 & 38751 & 0.35 & 5.66 & 2261 & 0.17 \\
\hline$n$-Hexane & 0.0014 & & 31.1 & 431 & 472 & 428300 & 0.34 & 5.57 & 2015 & 0.14 \\
\hline
\end{tabular}

Table 1 Spectral data and fluorescence quantum yield $\left(\phi_{f}\right)$ of ECPO dye in different solvents 


$$
\begin{gathered}
\Delta \bar{\nu}_{\mathrm{st}}=\frac{2\left(\mu_{\mathrm{e}}-\mu_{\mathrm{g}}\right)^{2}}{h c a^{3}} \Delta f+\text { const. } \\
\Delta f=\frac{\varepsilon-1}{2 \varepsilon+1}-\frac{n^{2}-1}{2 n^{2}+1}
\end{gathered}
$$

where $\Delta \nu$ is the Stokes shift which increases with increasing solvent polarity indicating stronger stabilization of singlet excited state in polar solvents, $h$ is Planck constant, $c$ is the speed of light and a is the Onsager cavity radius, $\varepsilon$ and $n$ are the dielectric constant and refractive index of the solvent, respectively. The constant represents higher order terms, which are usually neglected. The Onsager cavity radius was taken as 5.7 A. ${ }^{28}$ Fig. 4 shows the plot of Stokes shift versus the orientation polarizability $(\Delta f)$. The change of dipole moment $(\Delta \mu)$ upon excitation of 1.61 debye was calculated from the slope of the plot and the cavity radius. This change in dipole moment is caused by redistribution of atomic charges in the excited state as a result of charge transfer from the electron rich ethyl carbazole group to electron acceptor keto-group fragment.

The oscillator strength $(f)$ and transition dipole moment $\left(\mu_{12}\right)$ of electronic transition for ECPO from ground to excited singlet state $\left(\mathrm{S}_{0} \rightarrow \mathrm{S}_{1}\right)$ was calculated in different solvents using the following eqn (5) and (6). ${ }^{29}$

$$
\begin{aligned}
& f=4.32 \times 10^{-9} \int \varepsilon(\bar{\nu}) \mathrm{d} \bar{\nu} \\
& \mu_{12}{ }^{2}=\frac{f}{4.72 \times 10^{-7} E_{\max }}
\end{aligned}
$$

where $\varepsilon$ is the numerical value for molar extinction coefficient measured in $\mathrm{dm}^{3} \mathrm{~mol}^{-1} \mathrm{~cm}^{-1}, \nu$ is the value of wavenumber measured in $\mathrm{cm}^{-1}$ and $E_{\max }$ is the energy maximum of absorption band in $\mathrm{cm}^{-1}$. The values of $f$ and $\left(\mu_{12}\right)$ are listed in Table 1 and indicate that the $S_{0} \rightarrow S_{1}$ is a strongly allowed transition.

The empirical Dimroth polarity parameter, $E_{\mathrm{T}}(30)$ and $E_{\mathrm{T}}^{\mathrm{N}}$ of ECPO were also calculated according to the following equation. ${ }^{30,31}$

$$
E_{\mathrm{T}}^{\mathrm{N}}=\frac{E_{\mathrm{T}}(\text { solvent })-30.7}{32.4}
$$

$$
E_{\mathrm{T}}(\text { solvent })=\frac{28591}{\lambda_{\max }}
$$

where $\lambda_{\text {max }}$ corresponds to the peak wavelength (nm) in the red region of the intramolecular charge transfer absorption of ECPO. The red (bathochromic) shift from $n$-hexane to DMSO indicates that the photoinduced intramolecular charge transfer (ICT) occurs in the singlet-excited state, and the polarity of ECPO, therefore, increases on excitation.

\section{Fluorescence quantum yield}

The fluorescence quantum yield $\left(\phi_{\mathrm{f}}\right)$ of ECPO depends strongly on the solvent properties (Table 1). The fluorescence quantum yield can be correlated with $E_{\mathrm{T}}(30)$ of the solvent, where $E_{\mathrm{T}}(30)$ is the solvent polarity parameter introduced by Reichardt (see Fig. 5). ${ }^{32}$

The fluorescence quantum yield of ECPO increases with increasing solvent polarity from 0.14 in a non-polar solvent $n$ hexane to 0.19 in a moderately polar solvent DMSO with a further increase in solvent polarity the fluorescence quantum yield seems to decrease, i.e. 0.09 in a strongly polar solvent, $\mathrm{CH}_{3} \mathrm{OH}$. This indicates the occurrence of negative and positive solvatokinetic effects during the course of increasing solvent polarity. ${ }^{33}$ One main reason for the negative solvatokinetic effect (increase $\phi_{\mathrm{f}}$ with a suitable enhancement of ICT) could be due to the biradicaloid charge transfer involving the un-bridged double bonds and the other cause could be related to the proximity effect for compounds with $n-\pi^{*}$ and $\pi-\pi^{*}$ electron configurations. ${ }^{34}$ In other words, in non-polar solvents, these effects will result in effective nonradiative decay of the excited states. In strong polar solvents, the fluorescence quantum yield decreases due to a large degree of intramolecular charge transfer, which causes an increase in the rate of radiationless relaxation of an excited state, giving rise to a positive solvatokinetic effect (reduction in $\phi_{\mathrm{f}}$ by strong ICT). Moreover, the lower fluorescence quantum yields in proton solvents can be attributed to the hydrogen bond interaction between the molecule and surrounding solvent, which results in an

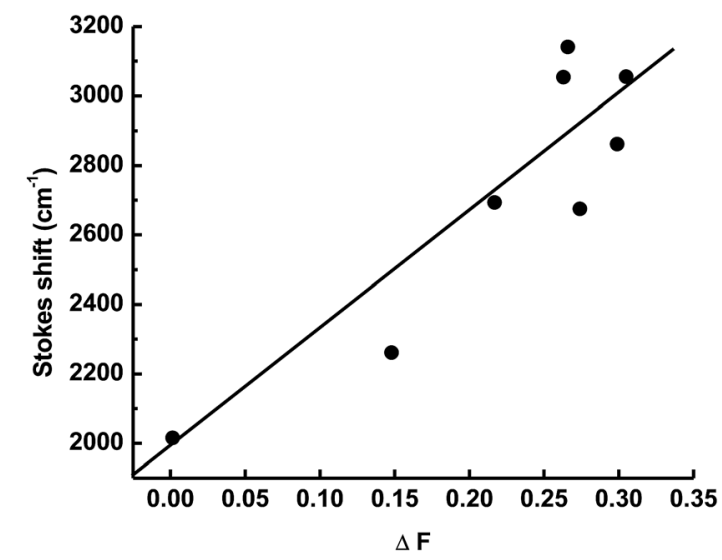

Fig. 4 Plot of $\Delta F$ versus Stokes shift $(\Delta \nu)$.

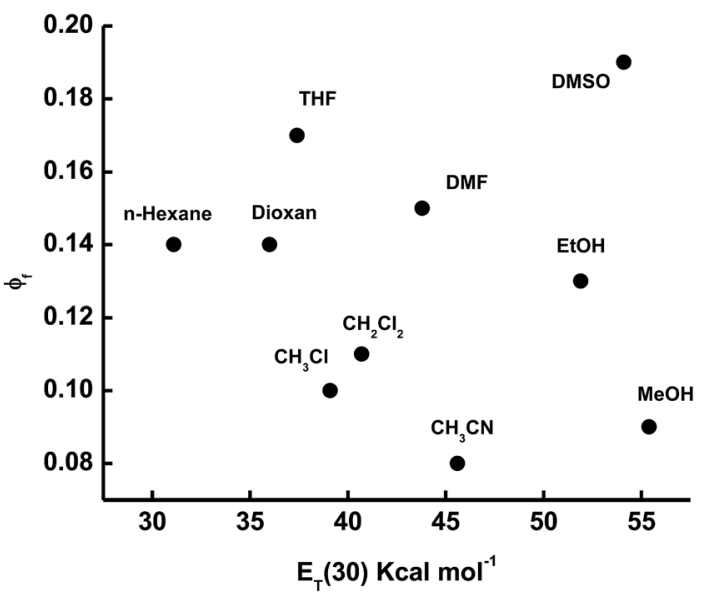

Fig. 5 Plot of $\phi_{\mathrm{f}}$ versus $E_{\mathrm{T}}(30)$ for the elected solvents. 
additional nonradiative decay as observed in other dipolar molecules.

\section{Effect of surfactant on emission spectrum of ECPO}

The emission spectrum of $1 \times 10^{-5} \mathrm{~mol} \mathrm{dm}^{-3}$ of ECPO has also been measured in cetyltrimethyl ammonium bromide (CTAB) cationic micelle and sodium dodecyl sulphate (SDS) anionic micelle. As shown in Fig. 6 and 7, the emission intensity of ECPO in aqueous solutions of surfactants increases with increasing concentration of surfactant, an abrupt change in fluorescence intensity is observed at surfactant concentration of $8.56 \times 10^{-4}$ and $5.42 \times 10^{-3} \mathrm{~mol} \mathrm{dm}{ }^{-3}$ which are very close to the critical micelle concentration (CMC) of SDS and CTAB, respectively. ${ }^{35}$ This indicates that ECPO can be employed as a probe for determining the CMC of surfactants (see Fig. 8 and 9). It was well known that aromatic molecules are generally solubilized in the palisade layer of micelle. ${ }^{36,37}$ Thus, the

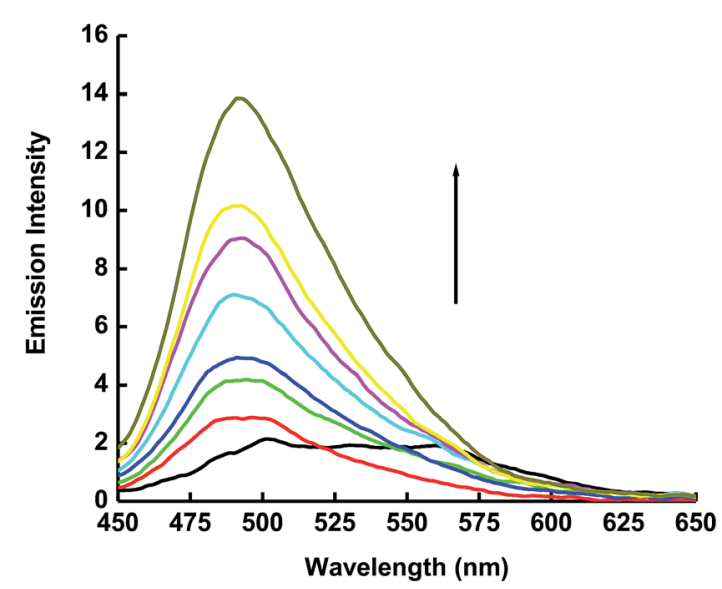

Fig. 6 Emission spectrum of $1 \times 10^{-5} \mathrm{~mol} \mathrm{dm}^{-3}$ of the ECPO dye at different concentrations of CTAB. The concentrations of CTAB at increasing emission intensity are $0.0,2 \times 10^{-4}, 4 \times 10^{-4}, 6 \times 10^{-4}, 8 \times$ $10^{-4}, 10 \times 10^{-4}, 12 \times 10^{-4}, 16 \times 10^{-4}$ and $18 \times 10^{-4} \mathrm{~mol} \mathrm{dm}^{-3}$.

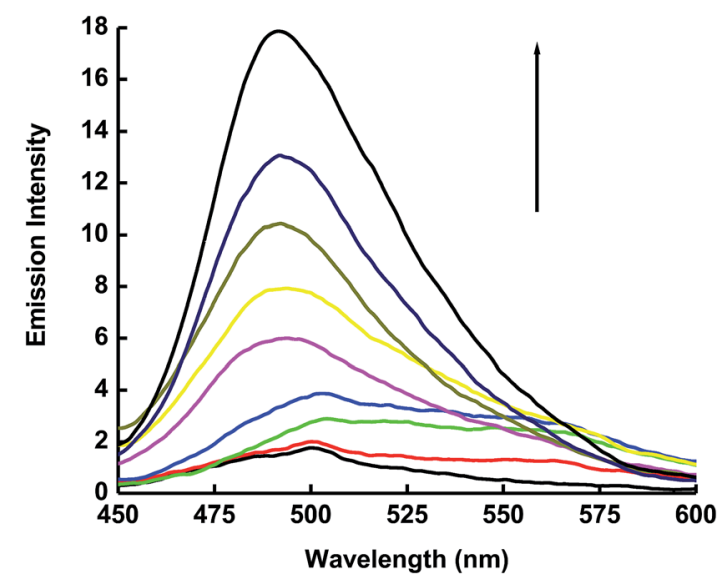

Fig. 7 Emission spectrum of $1 \times 10^{-5} \mathrm{~mol} \mathrm{dm}^{-3}$ of the ECPO dye at different concentrations of SDS. The concentrations of SDS at increasing emission intensity are $0.0,2 \times 10^{-3}, 4 \times 10^{-3}, 6 \times 10^{-3}, 8 \times$ $10^{-3}, 10 \times 10^{-3}, 12 \times 10^{-3}, 16 \times 10^{-3}$ and $18 \times 10^{-3} \mathrm{~mol} \mathrm{dm}^{-3}$. enhancement of emission intensity is attributed to the passage of dye molecule from the aqueous bulk solution to the palisade layer of micelle. The decrease in polarity of the microenvironment around dye molecule results in the reduction of nonradiative rate from ICT state to low-laying singlet or triplet state due to the enlargement of the energy gap between them, which leads to an increase in emission intensity.

\section{Synthesis of silver nanoparticle (AgNPs)}

Silver nanoparticles (AgNPs) were prepared by the citrate reduction of silver nitrate $\left(\mathrm{AgNO}_{3}\right)$. An aqueous solution of $\mathrm{AgNO}_{3}(1 \mathrm{~nm}, 125 \mathrm{ml})$ was heated until begins to boil, and then $5 \mathrm{ml}$ of a $1 \%$ trisodium citrate solution (as a nucleating and reducing agent) was added quickly, which resulted in a change in solution color to pale yellow. After the color change, the solution was removed from the heating element, allowed to stir unlit cool to room temperature. The nanoparticles were characterized by using UV-Vis absorption spectrophotometer and Transmission Electron Microscope (TEM). A typical solution of $0.2 \mu \mathrm{m}$ diameter silver nanoparticle exhibiting a characteristic surface plasmon band around $420 \mathrm{~nm}$ was obtained and confirmed by the TEM analysis as shown in Fig. 10 .

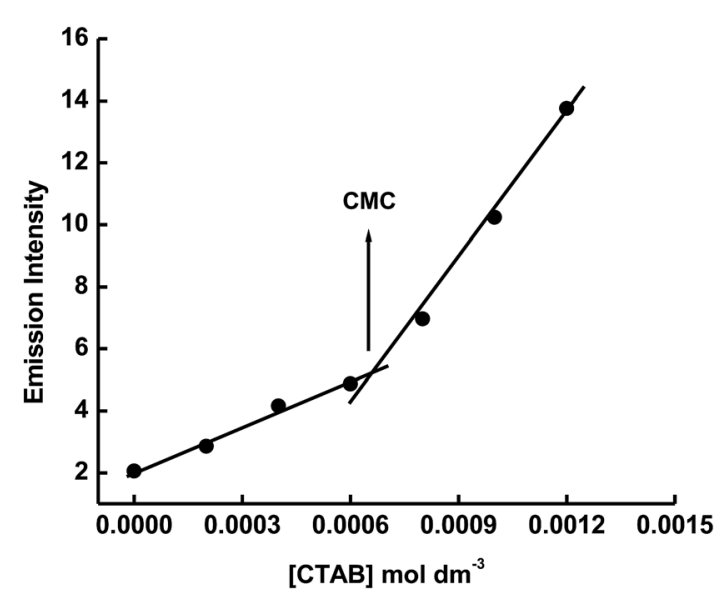

Fig. 8 Plot of $I_{f}$ versus the concentration of CTAB.

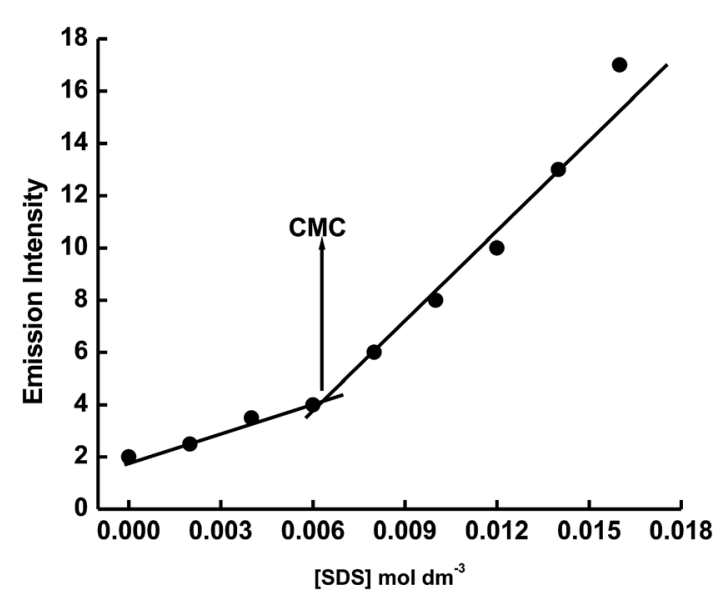

Fig. 9 Plot of $I_{\mathrm{f}}$ versus the concentration of SDS. 


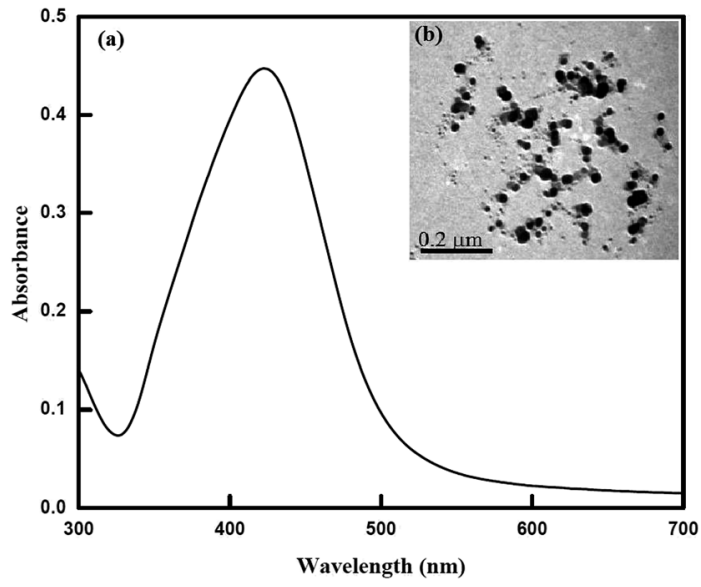

Fig. 10 (a) Absorbance spectrum of AgNPs $\left(\lambda_{\max }=420 \mathrm{~nm}\right)$ and (b) TEM image of AgNPs.

\section{Fluorescence quenching study of ECPO by silver nanoparticles}

The interaction of ECPO dye with AgNPs in solution was studied by fluorescence quenching measurements with different concentrations of AgNPs in ethanol and ethylene glycol (see Fig. 11). The emission spectra of $1 \times 10^{-5} \mathrm{~mol} \mathrm{l}^{-1}$ solution of ECPO in ethanol and ethylene glycol with different concentrations of AgNPs at $\lambda_{\mathrm{ex}}=430 \mathrm{~nm}$ are shown in Fig. 12 ((a) and (b), respectively). Fluorescence emission spectra of ECPO in the absence and presence of AgNPs were measured. On increasing the concentration of AgNPs, the emission spectrum of ECPO remains unaffected in wavelength but a substantial decrease in fluorescence intensity was observed; which rules out the possibility of ground state complex formation between ECPO and AgNPs.

The Stern-Volmer quenching constants $\left(K_{\mathrm{sv}}\right)$ for ECPO using AgNPs as a quencher were obtained from the Stern-Volmer eqn (9)..$^{38}$

$$
\frac{I_{0}}{I}=1+K_{\mathrm{sv}}\left[\mathrm{Ag}^{0}\right]
$$

where $I_{0}$ and $I$ are the fluorescence intensities in the absence and presence of the quencher concentration $\left[\mathrm{Ag}^{0}\right]$. The SternVolmer plot for (Fig. 13(a) and (b)) was found to be linear with correlation coefficient $\left(R^{2}\right)$ equal to 0.99 and 0.97 in ethanol and ethylene glycol, respectively. From the slopes of the linear plots, $K_{\text {sv }}$ values were calculated as $5.28 \times 10^{7} \mathrm{M}^{-1}$ and $3.48 \times 10^{7} \mathrm{M}^{-1}$ in ethanol and ethylene glycol, respectively [see Fig. 13(a) and (b)]. The higher value for $K_{\mathrm{sv}}$ in ethylene glycol implies that
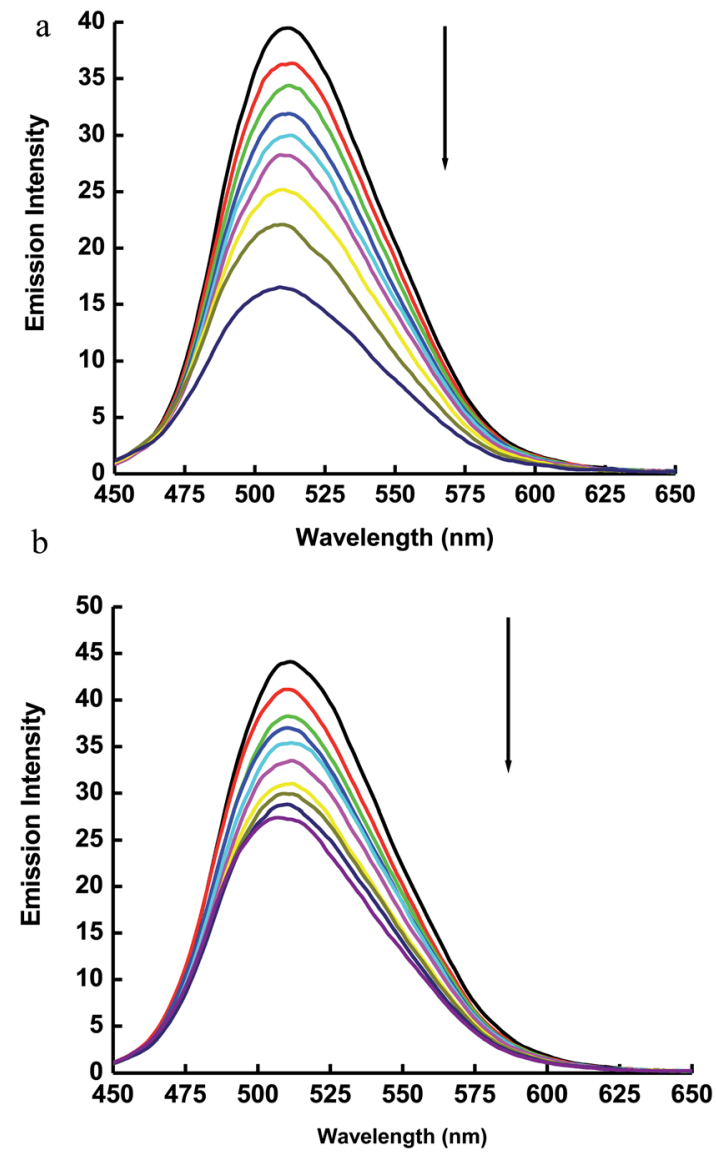

Fig. 12 (a) Emission spectra of $1 \times 10^{-5} \mathrm{~mol} \mathrm{l}^{-1}$ of the ECPO dye in ethanol in presence of different concentrations of AgNPs. The concentrations of AgNPs at decreasing emission intensity are 0.0, $0.1 .97,3.94,5.91,7.88,9.85,11.82,15.76$, and $17.23 \mathrm{nM}\left(\lambda_{\text {ex }}=370 \mathrm{~nm}\right)$. (b) Emission spectra of $1 \times 10^{-5} \mathrm{~mol} \mathrm{l}^{-1}$ of the ECPO dye in ethylene glycol in presence of different concentrations of AgNPs. The concentrations of AgNPs at decreasing emission intensity are 0.0, $0.1 .97,3.94,5.91,7.88,9.85,11.82,15.76$, and $17.23 \mathrm{nM}\left(\lambda_{\text {ex }}=430 \mathrm{~nm}\right)$.

the quenching efficiency increases as the medium viscosity increases and the quenching process is not completely diffusion controlled. Thus, the Stern-Volmer plot and the spectral overlap between the ECPO and AgNPs indicate the dynamic nature of the quenching process. The interaction between adsorbed and unadsorbed ECPO molecules was further investigated by determining the apparent association constant $\left(K_{\text {app }}\right)$ using Benesi-Hildebrand metho, ${ }^{39}$ eqn (10)-(12)

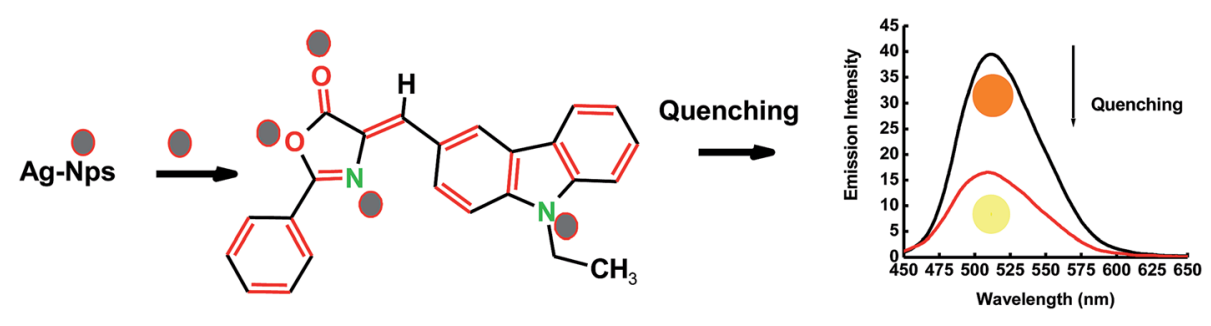

Fig. 11 A schematic representation of the formation of the ECPO-AgNPs interactions. 


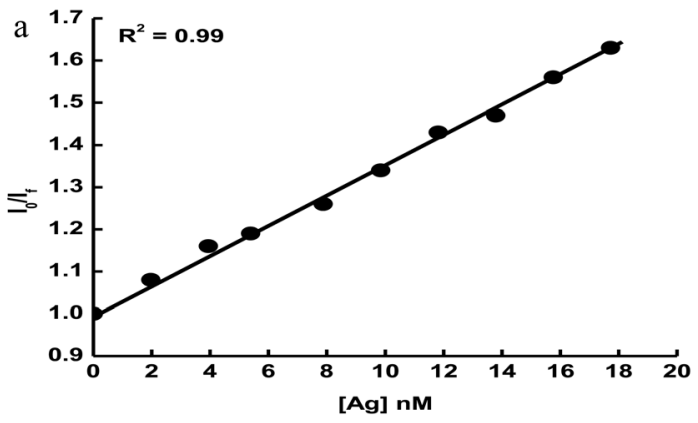

b

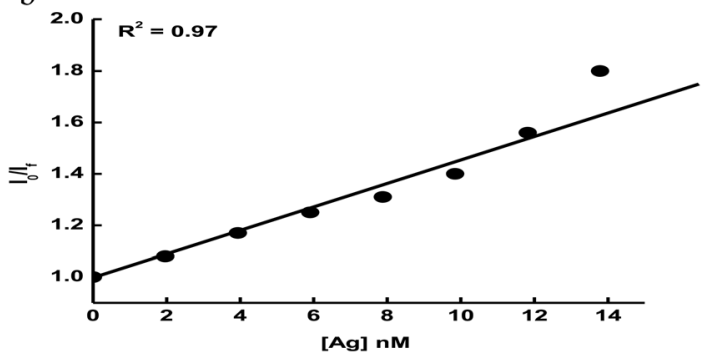

Fig. 13 (a) Stern-Volmer plot for fluorescence quenching of the ECPO dye by AgNPs in ethanol. (b) Stern-Volmer plot for fluorescence quenching of ECPO by AgNPs ethylene glycol.

$$
\begin{gathered}
\mathrm{ECPO}+\mathrm{Ag}=[\mathrm{ECPO} \cdots \mathrm{Ag}] \\
K_{\text {app }}=\frac{[\mathrm{ECPO} \cdots \mathrm{Ag}]}{[\mathrm{ECPO}][\mathrm{Ag}]} \\
\frac{1}{F^{0}-F}=\frac{1}{F^{0}-F^{\prime}}+\frac{1}{K_{\text {app }}} \times \frac{1}{F^{0}-F^{\prime}[\mathrm{Ag}]}
\end{gathered}
$$

where, $K_{\text {app }}$ is the apparent association constant, $F^{0}$ is the initial fluorescence intensity of dye molecules, $F^{\prime}$ is the fluorescence intensity of $\mathrm{Ag}$ adsorbed dye and $F$ is the observed fluorescence intensity at its maximum. The calculated values of $K_{\text {app }}$ obtained from the plot of $1 / F^{0}-F$ vs. $1 /[\mathrm{Ag}]$ (Fig. 14(a) and (b)) are found to be $4.26 \times 10^{8}$ and $1.99 \times 10^{8} \mathrm{M}^{-1}$ for ethanol and ethylene glycol, respectively. The higher value of $K_{\text {app }}$ indicates the strong association between the ECPO and AgNPs.

The interaction between ECPO dye molecules and AgNPs is presented schematically in Fig. 11. The dye molecule has four donor atoms: two nitrogen and two oxygen with which it can bind with AgNPs. With these electronegative nitrogen and oxygen groups, the dye can bind to AgNPs significantly to form an ECPO-AgNPs complex. Due to the affinity of ECPO molecule to AgNPs, electron transfer becomes easier as is evident from the earlier fluorescence measurements (Fig. 15). Furthermore, the significant spectral overlap between the emission spectrum of the dye with the absorption of spectrum of AgNPs reveals the possibility of nonradiative energy transfer from the dye to AgNPs according to Forster's theory. ${ }^{40}$

\section{DFT calculations}

The molecular orbital calculations were performed using the Gaussian09 Suites of programs ${ }^{\mathbf{4 1}}$ and viewed by applying GaussView Package. ${ }^{\mathbf{4 2}}$ The global minimum of the potential
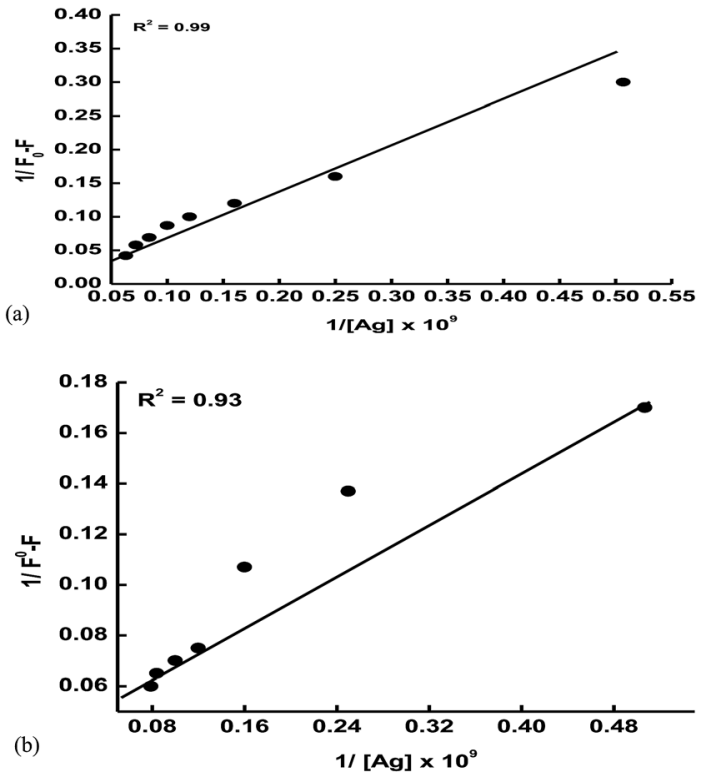

Fig. 14 Benesi-Hildebrand plot for the adsorption of the ECPO dye on AgNPs: (a) in ethanol and (b) in ethylene glycol.

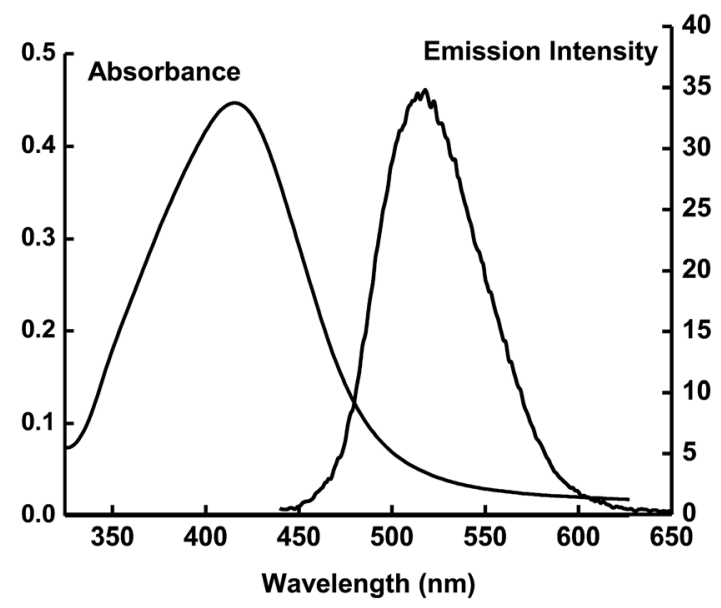

Fig. 15 Spectral overlap of absorption spectrum of AgNPs with the emission spectrum of the ECPO dye.

energy surface of the optimized structure of ECPO was obtained by using the long-range corrected (LC) column-attenuating method of the hybrid Becke's three parameter Lee-YoungParr correlation functional (CAM-B3LYP) ${ }^{43}$ of the density functional theory (DFT) with triple-zeta and polarization functions on hydrogen and heavy atoms basis set $\left[6-311++\mathrm{G}^{* *}\right]$. ECPO was dissolved in dimethyl sulphoxide (DMSO), acetonitrile $\left(\mathrm{CH}_{3} \mathrm{CN}\right)$, methanol $\left(\mathrm{CH}_{3} \mathrm{OH}\right)$, ethanol $\left(\mathrm{C}_{2} \mathrm{H}_{5} \mathrm{OH}\right)$, tetrahydrofuran (THF), dichloromethane $\left(\mathrm{CH}_{2} \mathrm{Cl}_{2}\right)$, chloroform $\left(\mathrm{CHCl}_{3}\right)$ and carbon tetrachloride $\left(\mathrm{CCl}_{4}\right)$ solvents. The absorption and emission spectra of ECPO in these solvents are simulated using time-dependent density functional theory (TD-DTF) ${ }^{\mathbf{4 4}}$ and the polarizable continuum model (PCM) method $^{45}$ with CAMB3LYP/6-311++G** level of theory. The non-linear optical (NLO) hyperpolarizabilities for gas-phase and solvated ECPO were 
estimated by using CAM-B3LYP/6-311++G** level of theory. Version 3.1 of the natural bond orbital (NBO) program ${ }^{46}$ was used to investigate the electric charges and delocalization energies of ECPO.

\section{Geometry optimization}

In Fig. 13 is shown the optimized structure of ECPO which has been obtained by using CAM-B3LYP/6-311++G** level of theory. A few bond lengths and angles of ECPO substrate optimized structure are listed in Table 2. Closer looks at Table 2 and Fig. 16 came up with the following observations: (1) the carbazole, isoxazole and benzene rings together with the vinyl and methylene groups are perfectly coplanar. This is evident from the nearly $180^{\circ}$ or $0.00^{\circ}$ dihedral angles over the entire compound; (2) only the methyl group is out-of-plane with $c a .90^{\circ}$ dihedral angle with the plane of the rings; (3) the C14-C28 and C33-C36 of $1.447 \AA$ and $1.459 \AA$, respectively, are shorter than the "normal" C-C single bonds as compared to propene ${ }^{47}$ and 2propene-1-imine. ${ }^{48}$ These partial multiple bonds indicates the charge transfer from the carbazole and benzene rings toward the isoxazole ring. (4) The $\mathrm{sp}^{2}$ hybridization scheme over the entire substrate is shown the bond angles of $116.8-133.6^{\circ}$.

\section{Frontier molecular orbitals (FMOs) and UV-visible spectra}

Frontier Molecular Orbitals (FMOs) investigations have proven to be extremely useful in understanding the electronic transitions

Table 2 Some selected bond lengths $(\AA)$, bond angles and dihedral angles (degrees) of ECPO which have been estimated by using CAMB3LYP/6-311++G** level of theory

\begin{tabular}{llll}
\hline Parameter & Bond length & Parameter & Bond angle \\
\hline C2-C3 & 1.385 & C11-N20-C21 & 125.8 \\
C4-N20 & 1.389 & C11-C12-C13 & 118.4 \\
N20-C21 & 1.450 & C13-C14-C28 & 123.0 \\
C11-C12 & 1.396 & C14-C28-C30 & 130.3 \\
C14-C28 & 1.447 & C30-C3-1O34 & 133.6 \\
C28-C30 & 1.346 & C31-O35-C33 & 106.2 \\
C31-O34 & 1.191 & O35-C33-C36 & 116.8 \\
C31-O35 & 1.396 & C16-C11-N20-C21 & 177.3 \\
O35-C33 & 1.369 & C16-C15-C14-C28 & 179.9 \\
C33-C36 & 1.459 & C13-C14-C28-C30 & 0.2 \\
C36-C37 & 1.394 & C28-C30-C31-O34 & 0.1 \\
C37-C38 & 1.396 & C37-C36-C33-O35 & 0.3
\end{tabular}

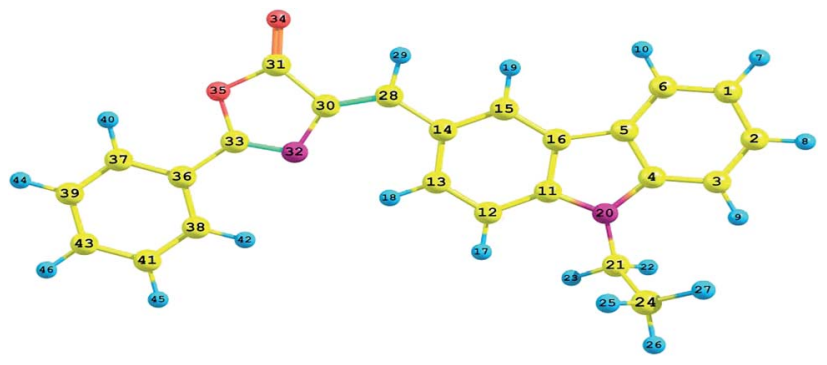

Fig. 16 The atom numbering of the ECPO dye. within molecules that lead to electronic properties like chemical reactivity, ionization potential (I.P.) and electron affinity (E.A.). ${ }^{49}$ The Highest Occupied Molecular Orbital (HOMO) is a donor orbital while the Lowest Unoccupied Molecular Orbital (LUMO) is an acceptor orbital. The energy of the former corresponds to the I.P. whereas that of the latter leads to the E.A. ${ }^{50}$ The HOMO and LUMO surfaces of gas-phase ECPO obtained by using CAMB3LYP/6-311++G** level of theory are shown in Fig. 17. The energies of HOMOs, LUMOs, Energy Gaps (E.G.), the electronic chemical potential $(\mu)$, the chemical hardness $(\eta)$, and the global electrophilicity index $(\omega)$ in gas-phase and various solvents, like carbon tetrachloride $\left(\mathrm{CCl}_{4}\right)$, chloroform $\left(\mathrm{CHCl}_{3}\right)$, tetrahydrofuran (THF), dichloromethane $\left(\mathrm{CH}_{2} \mathrm{Cl}_{2}\right)$, ethanol $\left(\mathrm{C}_{2} \mathrm{H}_{5} \mathrm{OH}\right)$, methanol $\left(\mathrm{CH}_{3} \mathrm{OH}\right)$, acetonitrile $\left(\mathrm{CH}_{3} \mathrm{CN}\right)$ and dimethyl sulphoxide (DMSO), are listed in Table 3. The HOMO is localized mainly on the carbazole ring as $\pi$-bonding orbital, while the LUMO extends over both the isoxazole and benzene rings as $\pi^{*}$-antibonding orbital. These HOMO and LUMO energies and related functions can be used to assign the kinetic stability of ECPO in these different solvents. Low energy gaps, low chemical hardness, high chemical potential, and high electrophilicity index can lead to less kinetic stability and high chemical reactivity because of intramolecular or intermolecular charge transfer..$^{51,52}$ As shown in Table 3, the HOMO-LUMO energy differences for gas-phase and solvated ECPO were found to be between 5.306 and $5.440 \mathrm{eV}$. They are inversely proportional to the polarity of the elected solvents; whereas the chemical potentials [-(4.176-4.324) eV] and electrophilicity indices (3.206-3.524 eV) are directly proportional to their dielectric constants. These results indicate that ECPO in DMSO is the softest, least stable and most reactive

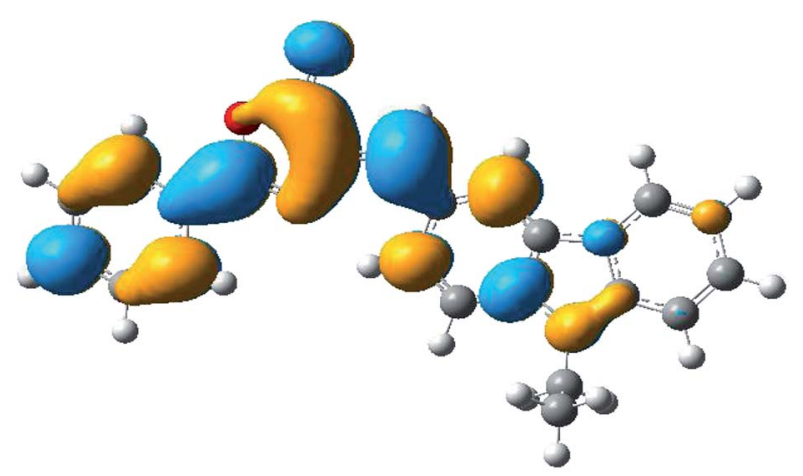

(a) LUMO : $E=-1.456 \mathrm{eV}$

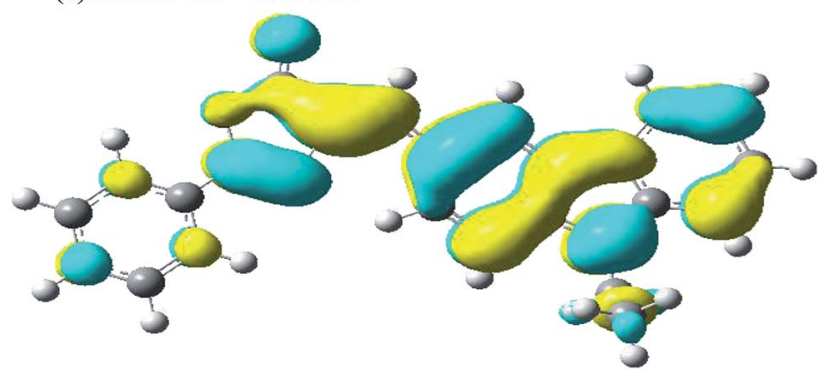

(b) HOMO: $\mathrm{E}=-6.896 \mathrm{eV}$ 
Table 3 The HOMO (eV), LUMO (eV) the energy gap (E.G./eV), the electronic chemical potential $(\mu / \mathrm{eV})$, the chemical hardness ( $\eta / \mathrm{eV})$, the global electrophilicity index $(\omega / \mathrm{eV})$ and total hyperpolarizability $\left(\beta_{\text {tot }} / \mathrm{a}\right.$.u. $)$ for ECPO in different solvents. They have been estimated applying CAM$B 3 L Y P / 6-31+G *$ level of theory

\begin{tabular}{|c|c|c|c|c|c|c|c|c|c|}
\hline Parameter & Gas-phase & $\mathrm{CCl}_{4}$ & $\mathrm{CHCl}_{3}$ & THF & $\mathrm{CH}_{2} \mathrm{Cl}_{2}$ & $\mathrm{C}_{2} \mathrm{H}_{5} \mathrm{OH}$ & $\mathrm{CH}_{3} \mathrm{OH}$ & $\mathrm{CH}_{3} \mathrm{CN}$ & DMSO \\
\hline НОМО & -6.896 & -6.937 & -6.958 & -6.966 & -6.968 & -6.975 & -6.976 & -6.976 & -6.977 \\
\hline LUMO & -1.456 & -1.554 & -1.613 & -1.635 & -1.642 & -1.664 & -1.667 & -1.669 & -1.671 \\
\hline D.M. & 6.276 & 7.393 & 8.039 & 8.284 & 8.359 & 8.608 & 8.643 & 8.653 & 8.677 \\
\hline$\mu$ & -4.176 & -4.246 & -4.286 & -4.301 & -4.304 & -4.320 & -4.322 & -4.323 & -4.324 \\
\hline$\eta$ & 2.720 & 2.692 & 2.673 & 2.666 & 2.663 & 2.656 & 2.655 & 2.654 & 2.653 \\
\hline
\end{tabular}

compared to the other solvated substrates, while being the harder, most stable and least reactive when dissolved in carbon tetrachloride. In addition, the electrophilicity indices show that the solvation of ECPO by DMSO yields the strongest electrophile within the solvated ECPOs, whereas being the weakest electrophile (or a nucleophile) when dissolved in carbon tetrachloride. ${ }^{53}$

$\pi$-Conjugated organic molecules are characterized by $\pi \rightarrow$ $\pi^{*}$ and $\mathrm{n} \rightarrow \pi^{*}$ electronic transitions and are therefore studied by U.V.-visible spectra; ${ }^{54}$ because of motions of electrons between the HOMOs and LUMOs. The studied molecule ECPO has many double bonds together with lone pairs on the oxygen and nitrogen atoms. The PCM/TD-B3LYP/6-31+G* theoretically simulated UV-visible maximum wavelengths of the absorption and emission spectra of ECPO in $\mathrm{CCl}_{4}, \mathrm{CHCl}_{3}, \mathrm{THF}, \mathrm{CH}_{2} \mathrm{Cl}_{2}$, $\mathrm{C}_{2} \mathrm{H}_{5} \mathrm{OH}, \mathrm{CH}_{3} \mathrm{OH}, \mathrm{CH}_{3} \mathrm{CN}$ and DMSO are listed in Table 4. The vertical absorption wavelengths maxima are obtained by single point TD-CAM-B3LYP/6-311++G** level of theory calculations on the ground state optimized geometries of ECPO in the elected solvents; whereas the adiabatic emission wavelengths maxima were simulated through the optimized geometries of the excited states of solvated ECPOs using the same level of theory. The absorption wavelength maxima range between 386 and $392 \mathrm{~nm}$; while the emission maxima lie between 456 and $512 \mathrm{~nm}$. It is quite clear that the computed maximum emission wavelengths are progressively red-shifted with the increase of the dielectric constants of the solvents. Likewise, their oscillator strengths are directly proportional to the polarity of these solvents. These theoretical predictions are in good agreement with our experimental results. The differences in magnitude between the observed (Table 1) and the calculated (Table 3) absorption and emission wavelength maxima could be related to the complexities imposed by the solvent effects..$^{55}$ The ground $\left(\mu_{\text {G.S. }}\right)$ and excited $\left(\mu_{\text {E.S. }}\right)$ state dipole moments of the solvated ECPOs and their difference $(\Delta \mu)$ are listed in Table 4 . The dipole moment differences range between 1.027 to 1.747 debye with an average of 1.534 debye which is in good agreement with our experimental value of 1.61 debye.

\section{Molecular electrostatic potential [MEP]}

Electronic cloud surfaces are termed Molecular Electrostatic Potentials [MEP]. These MEPs are used to describe the electrophilic and nucleophilic reacting sites as well as hydrogen bondings in molecules. ${ }^{56,57}$ As neighboring molecules interact with one another through their potentials; then their interactions could be approximated by the electrostatic potential $[V(r)]$, ignoring the polarization and reorganization effects, given by: ${ }^{58}$

$$
V(r)=\sum \frac{Z_{\mathrm{R}}}{R_{\mathrm{A}}-r}-\int \frac{\rho\left(r^{\prime}\right)}{r^{\prime}-r} \mathrm{~d} r^{\prime}
$$

where the summation $\left(\sum\right)$ runs over all nuclei $(\mathrm{A})$ of the molecule, $Z_{\mathrm{A}}$ is the charge of nucleus A located at $R_{\mathrm{A}}$ and $\rho\left(r^{\prime}\right)$ is the function of electron density of this molecule. Generally, the colours represent the electrostatic potential values at the MEP surfaces. The potential increases in the order: blue $>$ green $>$ yellow $>$ orange $>$ red. The resulting MEP surfaces are coloured red for nucleophilic sites and blue for electrophilic sites.

Table 4 The UV-Vis simulated maximum absorption $\left(\lambda_{\text {abs }} / \mathrm{nm}\right)$ and emission $\left(\lambda_{\mathrm{em}} / \mathrm{nm}\right)$ wavelengths and their oscillator strengths; together with the ground ( $\mu_{\mathrm{G} . \mathrm{S}}$ /debye) and excited ( $\left.\mu_{\mathrm{E} . \mathrm{S}} / \mathrm{debye}\right)$ and their difference $(\Delta \mu /$ debye) for the solvated ECPO dye, which were obtained by using TDCAM-B3LYP/6-31+G* level of theory. The dielectric constants of solvents were also included as measures for the polarity of solvents

\begin{tabular}{|c|c|c|c|c|c|c|c|c|}
\hline Solvent & $\lambda_{\mathrm{abs}} / \mathrm{nm}$ & $\begin{array}{l}\text { Oscillator } \\
\text { strength }\end{array}$ & $\lambda_{\mathrm{em}} / \mathrm{nm}$ & $\begin{array}{l}\text { Oscillator } \\
\text { strength }\end{array}$ & $\begin{array}{l}\text { Dielectric } \\
\text { constant }\end{array}$ & $\mu_{\text {G.S. }}$ & $\mu_{\text {E.S. }}$ & $\Delta \mu$ \\
\hline $\mathrm{CCl}_{4}$ & 386.09 & 1.433 & 465.62 & 1.462 & 2.24 & 7.393 & 8.420 & 1.027 \\
\hline $\mathrm{CHCl}_{3}$ & 389.13 & 1.434 & 488.47 & 1.550 & 4.81 & 8.039 & 9.399 & 1.349 \\
\hline THF & 389.42 & 1.425 & 497.38 & 1.580 & 7.59 & 8.284 & 9.772 & 1.488 \\
\hline $\mathrm{CH}_{2} \mathrm{Cl}_{2}$ & 390.35 & 1.430 & 500.13 & 1.589 & 8.93 & 8.359 & 9.892 & 1.533 \\
\hline Ethanol & 390.02 & 1.415 & 509.39 & 1.618 & 24.50 & 8.608 & 10.299 & 1.691 \\
\hline Methanol & 389.23 & 1.406 & 510.69 & 1.622 & 32.70 & 8.643 & 10.357 & 1.714 \\
\hline Acetonitrile & 389.77 & 1.411 & 511.05 & 1.623 & 36.71 & 8.653 & 10.373 & 1.720 \\
\hline DMSO & 391.99 & 1.430 & 511.97 & 1.626 & 46.68 & 8.668 & 10.414 & 1.747 \\
\hline
\end{tabular}


Fig. 18(a) and (b) show the MEP surfaces for the ground and excited states of gas-phase ECPO using TD-HF/6-31G* level of theory. The deep red coded region is around O34 of the isoxazole ring with values of -0.06631 a.u. and -0.06892 a.u. for the ground and excited states, respectively. In contrast, the pale blue coded region is around the ethyl group and N20 of the carbazole ring with values of 0.03318 a.u. and 0.03796 a.u. for the ground and excited states, respectively. Fig. 18(c) characterizes the charge transfer states of ECPO dye according to the plot of the difference in total electronic density between its ground and first excited states. It shows a greater degree of charge-transfer with the excited state gaining much density in the isoxazole ring.

It is clear that the carbonyl oxygen atom in the isoxazole ring that bears the largest negative charge in the excited state could easily bind to $\mathrm{Ag}^{+}$or AgNPs through its large lone pair. This ties up nicely with our experimental observation that the ECPOAgNPs complex forms between excited state ECPO and $\mathrm{Ag}^{+}$or AgNPs; and complemented by the excellent agreement between the theoretical emission wavelength of $509.39 \mathrm{~nm}$ in ethanol and its experimental rival of $511 \mathrm{~nm}$ in the same solvent.

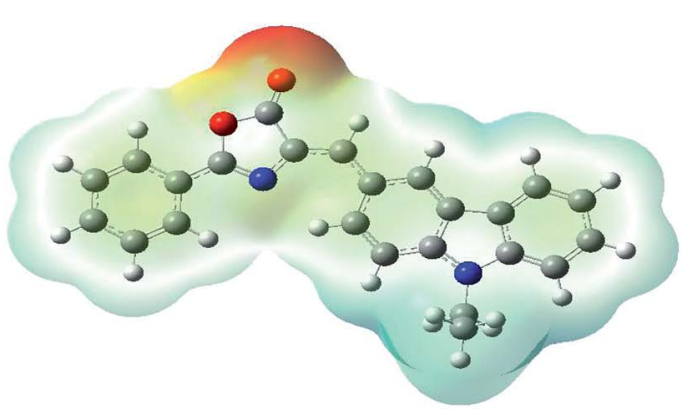

(a) Excited State

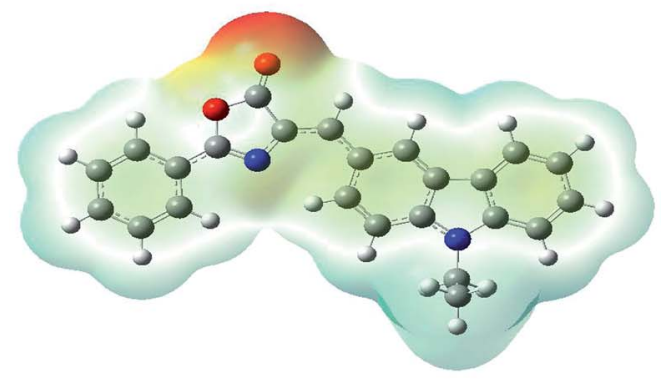

(b) Ground State

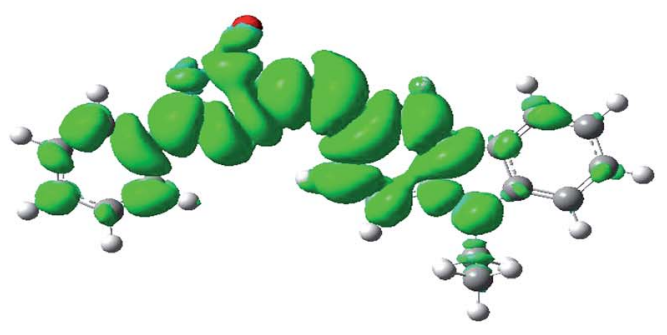

(c) MEP difference between Ground and Excited States.

Fig. 18 The MEP for the ECPO dye simulated by using TD-HF/631G* level of theory.

\section{Natural bond orbital (NBO) analysis}

Natural bond orbital (NBO) analysis is an efficient tool for investigating intra- and intermolecular bonding and provides a helpful technique for probing charge transfer or hyperconjugative interactions. ${ }^{59}$ The NBO analysis is a quantitative approach that expresses the bonding and antibonding interactions by means of second order perturbation energies $E^{(2)}$ given by the relation: ${ }^{60-63}$

$$
E^{(2)}=q_{i} \frac{F^{2}(i, j)}{\varepsilon_{j}-\varepsilon_{i}}
$$

where $q_{i}$ is the donor orbital occupancy, $\varepsilon_{i}$ and $\varepsilon_{j}$ are the orbital energies and $F^{2}(i, j)$ are the off-diagonal matrix elements. The values of $E^{(2)}$ measure the extent of interaction between the donor and acceptor orbitals that is reflected in the conjugation of the whole system. The most efficacious interactions between the occupied Lewis type (bond or lone pair) NBO orbitals with unoccupied non-Lewis (anti-bonding or Rydberg) NBO orbitals of ECPO are computed by applying $\mathrm{HF} / 6-31+\mathrm{G}^{*}$ level of theory and listed in Table 5. This calculation showed that the ECPO dye has a Lewis structure of $96.34 \%$ character, valence non-Lewis of $2.39 \%$ and Rydberg non-Lewis of $0.22 \%$. The most influential intramolecular hyperconjugative interactions involve the transfer of charge from $\pi$-bonding donor to $\pi^{*}$-antibonding acceptor orbitals; and from donor lone pairs (n) to $\pi^{*}$-antibonding acceptor or $\sigma^{*}$-antibonding orbitals. The $\pi \rightarrow \pi^{*}$ interactions avail $471.19 \mathrm{kcal} \mathrm{mol}^{-1}$; while $\mathrm{n} \rightarrow \pi^{*}$ and $\mathrm{n} \rightarrow \sigma^{*}$ contribute $265.94 \mathrm{kcal} \mathrm{mol}^{-1}$ for the stabilization of ECPO compound. On the one hand, the largest stabilization energy of $60.44 \mathrm{kcal} \mathrm{mol}^{-1}$ to the ECPO dye is by $\mathrm{n}_{1 \mathrm{~N} 20} \rightarrow \pi_{\mathrm{C} 11-\mathrm{C} 16}^{*}$ interaction. This is consistent with our MEP prediction that this region is highly electrophilic compared to other parts of the ECPO dye. On the other hand, the lone pairs on O34 and 035 atoms donation to antibonding $\sigma_{\mathrm{C} 31-\mathrm{O} 35}^{*}$ and $\pi_{\mathrm{C} 31-\mathrm{O} 35}^{*}$ orbitals have stabilized the ECPO substrate by 57.70 and 47.39 kcal $\mathrm{mol}^{-1}$, respectively. This rendered the region around $\mathrm{O} 35$ atom as the most nucleophilic site on the ECPO system. The shorter than expected $\mathrm{C} 14-\mathrm{C} 28$ and $\mathrm{C} 33-\mathrm{C} 36$ bonds resulted from the delocalization interactions $\pi_{\mathrm{C} 14-\mathrm{C} 15} \rightarrow \pi_{\mathrm{C} 28-\mathrm{C} 30}^{*}$ and $\pi_{\mathrm{C} 36-\mathrm{C} 37} \rightarrow \pi_{\mathrm{C} 33-\mathrm{N} 32}^{*}$ which contributed 32.23 and $29.79 \mathrm{kcal}$ $\mathrm{mol}^{-1}$, respectively, for the stabilization of the system. All other

Table 5 Some selected most efficacious second order perturbation $\left.{ }^{(2)}\right)$ assessment of the hyperconjugative energies $\left(\mathrm{kcal} \mathrm{mol}^{-1}\right)$ of the title compound (ECPO) which were computed applying HF/6-31+G* level of theory

\begin{tabular}{llll}
\hline Interaction & Energy & Interaction & Energy \\
\hline $\mathrm{n}_{1 \mathrm{~N} 20} \rightarrow \pi_{\mathrm{C} 4-\mathrm{C} 5}^{*}$ & 52.19 & $\pi_{\mathrm{C} 4-\mathrm{C} 5} \rightarrow \pi_{\mathrm{C} 1-\mathrm{C} 6}^{*}$ & 45.54 \\
$\mathrm{n}_{1 \mathrm{~N} 20} \rightarrow \pi_{\mathrm{C} 11-\mathrm{C} 16}^{*}$ & 60.44 & $\pi_{\mathrm{C} 11-\mathrm{C} 16} \rightarrow \pi_{\mathrm{C} 14-\mathrm{C} 15}^{*}$ & 56.15 \\
$\mathrm{n}_{1 \mathrm{O} 34} \rightarrow \sigma_{\mathrm{C} 31-\mathrm{O} 35}^{*}$ & 57.70 & $\pi_{\mathrm{C} 12-\mathrm{C} 13} \rightarrow \pi_{\mathrm{C} 11-\mathrm{C} 16}^{*}$ & 43.50 \\
$\mathrm{n}_{2 \mathrm{O} 35} \rightarrow \pi_{\mathrm{C} 31-\mathrm{O} 34}^{*}$ & 47.39 & $\pi_{\mathrm{C} 14-\mathrm{C} 15} \rightarrow \pi_{\mathrm{C} 12-\mathrm{C} 13}^{*}$ & 41.67 \\
$\mathrm{n}_{2 \mathrm{O} 35} \rightarrow \pi_{\mathrm{N} 32-\mathrm{C} 33}^{*}$ & 48.22 & $\pi_{\mathrm{C} 36-\mathrm{C} 37} \rightarrow \pi_{\mathrm{C} 38-\mathrm{C} 41}^{*}$ & 41.43 \\
$\pi_{\mathrm{C} 1-\mathrm{C} 6} \rightarrow \pi_{\mathrm{C} 2-\mathrm{C} 3}^{*}$ & 44.79 & $\pi_{\mathrm{C} 38-\mathrm{C} 41} \rightarrow \pi_{\mathrm{C} 39-\mathrm{C} 43}^{*}$ & 54.22 \\
$\pi_{\mathrm{C} 2-\mathrm{C} 3} \rightarrow \pi_{\mathrm{C} 4-\mathrm{C} 5}^{*}$ & 42.10 & $\pi_{\mathrm{C} 39-\mathrm{C} 43} \rightarrow \pi_{\mathrm{C} 36-\mathrm{C} 37}^{*}$ & 48.77 \\
$\pi_{\mathrm{C} 14-\mathrm{C} 15} \rightarrow \pi_{\mathrm{C} 28-\mathrm{C} 30}^{*}$ & 32.23 & $\pi_{\mathrm{C} 36-\mathrm{C} 37} \rightarrow \pi_{\mathrm{C} 33-\mathrm{N} 32}^{*}$ & 29.79
\end{tabular}


interactions facilitate the extended conjugative charge transfer interactions from the ethyl carbazole and benzene rings (donor sites) towards the isoxazole as an acceptor venue. Finally, this huge intramolecular charge transfer is facilitated by coplanarity of the carbazole, benzene and isoxazole rings.

\section{Nonlinear optical properties}

Lately, compounds acquiring nonlinear optical properties (NLO) have caught the attention of researchers due to their wide applications in optical switching, signal processing, telecommunications and information storage. ${ }^{64}$ Bartkowiak and Misiaszek have shown that $\pi$-electron conjugated systems with donor and acceptor moieties are considered highly promising NLO candidates. ${ }^{65}$

The ECPO dye having carbazole and benzene rings (electron donors) connected, through conjugated multiple bonds, to an isoxazole moiety (electron acceptor) is anticipated to exhibit very strong NLO properties. For the investigation of NLO characteristics, the total first hyperpolarizability $\left(\beta_{\text {tot }}\right)$ analysis of gas-phase and solvated ECPO has been carried out applying CAM-B3LYP/ 6-311++G** level of theory and listed in Table 3. The first total hyperpolarizability is $3 \times 3 \times 3$ matrix that results in 27 components being reduced to 10 components $^{66}$ in Gaussian09 program ${ }^{41}$ output file and given as: $\beta_{x x x}, \beta_{x x y}, \beta_{x y y}, \beta_{y y y}, \beta_{x x z}, \beta_{x y z}, \beta_{y y z}, \beta_{x z z}, \beta_{y z z}$ and $\beta_{z z z}$, respectively. From these components, the total hyperpolarizability $\left(\beta_{\text {tot }}\right)$ is computed as: ${ }^{67}$

$\beta_{\mathrm{tot}}=$

$\sqrt{\left(\beta_{x x x}+\beta_{x y y}+\beta_{x z z}\right)^{2}+\left(\beta_{y y y}+\beta_{x x y}+\beta_{y z z}\right)^{2}+\left(\beta_{z z z}+\beta_{x x z}+\beta_{y y z}\right)^{2}}$

In Table 3, the total hyperpolarizabilities are given in a.u., which are related to electrostatic units through the relation: 1 a.u. $=8.6393 \times 10^{-33}$ esu. On the one hand, the total hyperpolarizability for gas-phase ECPO is 6733 a.u. which is $c a$. six times greater than the experimental ${ }^{68}\left(1072 \pm 44\right.$ a.u.) or the theoretical ${ }^{69}$ (1337 a.u. using $\omega \mathrm{B} 97 \mathrm{XD} / 6-311+\mathrm{G}^{* *}$ level of theory) values for the reference charge transfer $\mathrm{D}-\pi-\mathrm{A} p$-nitroaniline $(p \mathrm{NA})$. On the other hand, the total hyperpolarizabilities for the ECPO dye in the elected solvents were $c a$. 2-3 times greater than its value in the gasphase. This agrees completely with the calculated total hyperpolarizability of methanol solvated $p \mathrm{NA}$ using $\omega \mathrm{B} 97 \mathrm{XD} / 6-311+\mathrm{G}^{* *}$ level of theory ${ }^{69}$ which has increased by nearly a factor of four compared to its value in gas-phase. In addition, our total hyperpolarizabilities for the ECPO dye in these solvents are directly proportional to the dielectric constants (polarities) of these solvents and likewise to the magnitudes of the dipole moments of the solvated ECPOs. These findings could be interpreted in terms of a high degree intermolecular solute-solvent charge transfer. As a consequence, our predictions could lead to the conclusion that the ECPO dye is a highly dynamic $\mathrm{D}-\pi-\mathrm{A}$ charge transfer suit, with excellent chance of being a highly potent NLO device.

\section{Conclusions}

(4Z)-4-[(9-Ethyl-9H-carbazol-3-yl)methylidene]-2-phenyl-1,3-oxazol-5(4H)-one (ECPO) was prepared by an equimolar quantities of multicomponent reaction of hippuric acid, 1-methyl-1 $H_{-}$ pyrrole-2-carbaldehyde and anhydrous sodium acetate in acetic anhydride. Physicochemical studies of the ECPO substrate including singlet absorption, extinction coefficient, Stokes shift, oscillator strength and dipole moment were investigated, experimentally and theoretically, based on the polarity of the solvents. The absorption and emission spectra of the ECPO dye exhibit an intramolecular charge transfer band; which showed a positive solvatochromism in different solvents. These findings confirm that there is a significant charge transfer between the donating moiety and the accepting fragment through $\pi$ conjugation. An NBO analysis complemented this significant charge transfer and pinpointed its origin. Consequently, the ECPO dye was predicted to be a highly potent NLO device based on its large total hyperpolarizability. The ECPO substrate undergoes solubilization in different micelles for the use in the determination of CMC of surfactants (SDS and CTAB). Newly synthesized AgNPs were used as quenchers for the ECPO dye through its interaction with AgNPs in ethanol and ethylene glycol. The fluorescence quenching data, the dynamic quenching and the energy transfer from the excited ECPO dye to the AgNPs play major roles in the fluorescence quenching of the dye by AgNPs. MEP surfaces confirmed these observations.

\section{Acknowledgements}

The authors are thankful to the Chemistry Department at King Abdulaziz University for providing research facilities.

\section{References}

1 R. Y. Iliashenko, O. O. Borodin, M. Wera and A. O. Doroshenko, J. Phys. Chem. A, 2015, 298, 68-77.

2 M. Jozefowicz, J. R. Heldt and J. Heldt, J. Lumin., 2012, 132, 755-764.

3 D. D. Babu, H. Cheema, D. Elsherbiny, A. El-Shafei and A. V. Adhikari, Electrochim. Acta, 2015, 176, 868-879.

4 M. Z. Yigit, H. Bilgili, E. Sefer, S. Demic, C. Zafer, M. Can and S. Koyuncu, Electrochim. Acta, 2014, 147, 617-625.

5 Y. Chen, F. Zhao, Y. Zhao, J. Chen and D. Ma, Org. Electron., 2012, 13, 2807-2815.

6 E. Hrishikesan and P. Kannan, Inorg. Chim. Acta, 2013, 37, 21-25.

7 Y. Yang, B. Li, L. Zhang and Y. Guan, J. Lumin., 2014, 145, 895-898.

8 C. L. Honeybourne, J. Phys. Chem. Solids, 1987, 48, 109-141. 9 E. Iengo, P. Cavigli, D. Milano and P. Tecilla, Inorg. Chim. Acta, 2014, 417, 59-78.

10 M. Noh, T. Kim, H. Lee, C. Kim, S. Joo and K. Lee, Colloids Surf., A, 2010, 359, 39-44.

11 W. T. Ashton, R. M. Sisco, H. Dong, K. A. Lyons, H. He, G. A. Doss, B. Leiting, R. A. Patel, J. K. Wu, F. Marsilio, N. A. Thornberry and A. E. Weber, Bioorg. Med. Chem. Lett., 2005, 15, 2253-2258.

12 Y. Zheng, C. Yang, D. Zhang-Negrerie, Y. Du and K. Zhao, Tetrahedron Lett., 2013, 54, 6157-6160. 
13 Shamsuzzaman, M. S. Khan, M. Alam, Z. Tabassum, A. Ahmad and A. U. Khan, Eur. J. Med. Chem., 2010, 45, 1094-1097.

14 Z. Zhong, D. Zhang, Z. Peng, Y. Li, G. Shan, L. Zuo, L. Wu, S. Li, R. Gao and Z. Li, Eur. J. Med. Chem., 2013, 69, 32-43.

15 I. H. R. Tomi, J. H. Tomma, A. H. R. Al-Daraji and A. H. AlDujaili, J. Saudi Chem. Soc., 2015, 19, 392-398.

16 C. Wei, L. Guan, J. Jia, K. Chai and Z. Quan, Arch. Pharmacal Res., 2009, 32, 23-31.

17 G. C. Moraski, M. Chang, A. Villegas-Estrada, S. G. Franzblau, U. Mollmann and M. J. Miller, Eur. J. Med. Chem., 2010, 45, 1703-1716.

18 C. K. Ryu, R. Y. Lee, N. Y. Kim, Y. H. Kim and A. L. Song, Bioorg. Med. Chem. Lett., 2009, 19, 5924-5926.

19 G. J. Drtina, L. C. Haddad, J. K. Rasmussen, B. N. Gaddam, M. G. Williams, S. J. Moeller, R. T. Fitzsimons, D. D. Fansler, T. L. Buhl, Y. N. Yang, V. A. Weller, J. M. Lee, T. J. Beauchamp and S. M. Heilmann, React. Funct. Polym., 2005, 64, 13-24.

20 K. Ertekin, S. Alp and I. Yalcın, Dyes Pigm., 2005, 65, 33-38. 21 C. Gao and D. Yan, Prog. Polym. Sci., 2004, 29, 183-227.

22 Y. Niko, Y. Hiroshige, S. Kawauchi and G. Konishi, Tetrahedron, 2012, 68, 6177-6185.

23 H. Bar, D. K. Bhui, G. P. Sahoo, P. Sarkar, S. P. De and A. Misra, Colloids Surf., A, 2009, 339, 134-139.

24 A. M. Asiri, S. A. El-daly and S. A. Khan, Spectrochim. Acta, Part A, 2012, 85, 679-684.

25 A. Teshome, M. D. H. Bhuiyan, G. J. Gainsford, M. Ashraf, I. Asselberghs, G. V. M. Williams, A. J. Kay and K. Clays, Opt. Mater., 2011, 33, 336-345.

26 L. Wang, Y. Zhang, Y. Li, H. He and J. Zhang, J. Photochem. Photobiol., A, 2014, 336, 14-19.

27 T. Stalin, G. Sivakumar, B. Shanthi, A. Sekar and N. Rajendiran, J. Photochem. Photobiol., A, 2006, 177, 144155.

28 S. Joshi, S. Kumari, R. Bhattacharjee, R. Sakhuja and D. D. Pant, J. Mol. Liq., 2015, 209, 219-223.

29 D. D. Thiare, A. Khonte, A. Diop, L. Cisse, A. Coly, A. Tine and F. Delattre, J. Mol. Liq., 2015, 211, 640-646.

30 H. M. Marwani, A. M. Asiri and S. A. Khan, J. Lumin., 2013, 136, 296-302.

31 M. Chastrette and J. Carretto, Tetrahedron, 1982, 38, 16151618.

32 P. K. Khatua, S. Chatterjee and S. C. Bhattacharya, J. Lumin., 2006, 121, 488-496.

33 S. Song, D. Ju, J. Li, D. Li, Y. Wei, C. Dong, P. Lin and S. Shuang, Talanta, 2009, 77, 1707-1714.

34 B. Varghese, S. N. Al-Busafi, F. O. Suliman and S. M. Z. AlKindy, Spectrochim. Acta, Part A, 2015, 136, 661-671.

35 H. Tajalli, A. G. Gilani, M. S. Zakerhamidi and M. Moghadam, Spectrochim. Acta, Part A, 2009, 72, 697-702.

36 A. Dutta and R. K. Dutta, J. Mol. Liq., 2013, 178, 25-30.

37 V. G. Rao, U. Brahmachari, S. Mandal, S. Ghosh, C. Banerjee and N. Sarkar, Chem. Phys. Lett., 2012, 552, 38-43.

38 S. A. Khan and A. M. Asiri, J. Mol. Liq., 2016, 221, 381-385.

39 M. Kadar, A. Biro, K. Toth, B. Vermes and P. Huszthy, Spectrochim. Acta, Part A, 2005, 62, 1032-1038.
40 S. R. Kavitha, M. Umadevi, S. R. Janani, T. Balakrishnan and R. Ramanibai, Fluorescence quenching and photocatalytic degradation of textile dyeing waste water by silver nanoparticles, Spectrochim. Acta, Part A, 2014, 127, 115-121.

41 M. J. Frisch, G. W. Trucks, H. B. Schlegel, G. E. Scuseria, M. A. Robb, J. R. Cheeseman, G. Scalmani, V. Barone, B. Mennucci, G. A. Petersson, H. Nakatsuji, M. Caricato, X. Li, H. P. Hratchian, A. F. Izmaylov, J. Bloino, G. Zheng, J. L. Sonnenberg, M. Hada, M. Ehara, K. Toyota, R. Fukuda, J. Hasegawa, M. Ishida, T. Nakajima, Y. Honda, O. Kitao, H. Nakai, T. Vreven, J. A. Montgomery Jr, J. E. Peralta, F. Ogliaro, M. Bearpark, J. J. Heyd, E. Brothers, K. N. Kudin, V. N. Staroverov, R. Kobayashi, J. Normand, K. Raghavachari, A. Rendell, J. C. Burant, S. S. Iyengar, J. Tomasi, M. Cossi, N. Rega, J. M. Millam, M. Klene, J. E. Knox, J. B. Cross, V. Bakken, C. Adamo, J. Jaramillo, R. Gomperts, R. E. Stratmann, O. Yazyev, A. J. Austin, R. Cammi, C. Pomelli, J. W. Ochterski, R. L. Martin, K. Morokuma, V. G. Zakrzewski, G. A. Voth, P. Salvador, J. J. Dannenberg, S. Dapprich, A. D. Daniels, O. Farkas, J. B. Foresman, J. V. Ortiz, J. Cioslowski, and D. J. Fox, Gaussian 09, Revision A.02, Gaussian, Inc., Wallingford CT, 2009.

42 A. Frisch, R. D. Dennington II, T. A. Keith, J. Milliam. A. B. Nielsen, A. J. Holder and J. Hiscocks, GaussView Reference, Version 5.0, Gaussian Inc, Pittsburgh, 2007.

43 T. Yanai, D. P. Tew and N. C. A. Handy, Chem. Phys. Lett., 2004, 393, 51-57.

44 E. K. U. Gross and W. Kohn, Adv. Quantum Chem., 1990, 21, 255-291.

45 E. Cances, B. Mennucci and J. Tomasi, J. Chem. Phys., 1997, 107, 3032-3041.

46 E. A. Reed, L. A. Curtiss and F. Weinhold, Chem. Rev., 1988, 88, 899-993.

47 G. Wlodarczak, J. Demaison, N. Heineking and A. G. Csaszar, J. Mol. Spectrosc., 1994, 167, 239-247.

48 R. E. Penn, J. Mol. Spectrosc., 1978, 69, 373-382.

49 J. Cornil, D. Beljonne, J.-P. Calbert and J.-L. Bredas, Adv. Mater., 2001, 13, 1053-1067.

50 I. Fleming, Frontier orbitals and organic chemical reactions, Wiley, London, 1976.

51 P. K. Chattaraj and B. Maiti, J. Am. Chem. Soc., 2003, 125, 2705-2710.

52 R. G. Pearson, J. Chem. Sci., 2005, 117, 369-377.

53 M. J. Aurell, R. L. Domingo, P. Perez and R. Contreras, Tetrahedron, 2004, 60, 11503-11509.

54 R. M. Silverstein, G. C. Bassler and T. C. Morrill, Spectrometric identification of organic compounds, John Wiley, Chistester, 1991.

55 M. Karabacak and M. Cinar, FT-IR, FT-Raman, Spectrochim. Acta, Part A, 2012, 86, 590-599.

56 E. Scrocco and J. Tomasi, Adv. Quantum Chem., 1978, 11, 115-121.

57 F. J. Luque, J. M. Lopez and M. Orozco, Theor. Chem. Acc., 2000, 103, 343-345.

58 P. Politzer, P. R. Laurence and K. Jayasuriya, Environ. Health Perspect., 1985, 61, 191-202. 
59 O. I. Osman, A. O. Alyoubi, S. A. K. Elroby, R. H. Hilal and S. G. Aziz, Int. J. Mol. Sci., 2012, 13, 15360-15372.

60 A. E. Reed and F. Weinhold, J. Chem. Phys., 1985, 83, 17361740.

61 A. E. Reed and F. Weinhold, J. Chem. Phys., 1985, 83, 735746.

62 A. E. Reed and F. Weinhold, J. Chem. Phys., 1983, 78, 40664073.

63 J. P. Foster and F. Weinhold, J. Am. Chem. Soc., 1980, 102, 7211-7721.
64 K. S. Thanthiriwatte and K. M. N. de Silva, J. Mol. Struct.: THEOCHEM, 2002, 617, 169-175.

65 W. Bartkowiak and T. Misiaszek, Chem. Phys., 2000, 261, 353-357.

66 D. A. Kleinman, Phys. Rev., 1962, 126, 1977-1979.

67 A. J. Garza, O. I. Osman, G. E. Scuseria, N. A. Wazzan and A. M. Asiri, Comput. Theor. Chem., 2013, 1022, 82-85.

68 P. Kaatz, E. A. Donley and D. P. Shelton, J. Chem. Phys., 1997, 108, 849-856.

69 A. J. Garza, O. I. Osman, A. M. Asiri and G. E. Scuseria, J. Phys. Chem. B, 2015, 119, 1202-1212. 